\title{
Trends in ectopic pregnancy: a retrospective clinical study of 79 cases
}

\author{
Sindhura M., Sailatha R.*, Famida A. M., Vijayalakshmi K., Sathiya S., Renuka S.
}

Department of Obstetrics and Gynecology, Chettinad Health and Research Institute, Chennai, Tamil Nadu, India

Received: 28 April 2017

Accepted: 22 May 2017

\section{*Correspondence:}

Dr. Sailatha R.,

E-mail: sailatha.ramanujam@rediffmail.com

Copyright: (C) the author(s), publisher and licensee Medip Academy. This is an open-access article distributed under the terms of the Creative Commons Attribution Non-Commercial License, which permits unrestricted non-commercial use, distribution, and reproduction in any medium, provided the original work is properly cited.

\section{ABSTRACT}

Background: To know the age group, parity, risk factors, clinical features, modalities of treatment employed and their efficacies, morbidity and mortality associated with ectopic pregnancy.

Methods: This is a retrospective study conducted in the department of Obstetrics and Gynaecology at Chettinad Hospital and Research Institute; Chennai over a period of 3 years from January 2014 to December 2016. A total number of 79 cases of ectopic pregnancies were reported during this period. Data were collected, tabulated and analyzed.

Results: 79 cases were diagnosed as ectopic pregnancies during the study period giving an incidence of $3.49 \%$. Incidence of cases was maximum in women between the age group of $26-30$ years $(40.50 \%)$, in multiparous women $(72.15 \%)$ and also in women of gestational age between 6 to 10 weeks $(81.01 \%) .72 \%$ of the cases had one or more identifiable risk factors. Ruptured ectopic was observed in 45 (56.96\%)cases while unruptured in 31 (39.24\%) cases. Tubal abortion was found in $3(3.74 \%)$ cases. $2.53 \%$ cases were expectantly managed. $34.17 \%$ cases were medically managed. $63.29 \%$ cases were managed surgically. Morbidity due to ectopic pregnancy included anaemia, wound infection, SICU admission. No mortality observed.

Conclusions: A high index of suspicion is needed in the diagnosis of ectopic pregnancy especially in women with high risk factors to arrive at early diagnosis, followed with conservative management, thus reducing the morbidity. We can reduce the incidence of ectopic pregnancy by awareness on safe sexual practices and contraception. The lady's future fertility can be improved by focusing on prevention, early diagnosis and conservative management of ectopic pregnancy.

Keywords: Ectopic pregnancy, Haemoperitoneum, Methotrexate, Salpingectomy

\section{INTRODUCTION}

Ectopic pregnancy is defined as any intra or extrauterine pregnancy in which the fertilized ovum implants at an aberrant site which is inconducive to its growth and development. ${ }^{1}$ It is the major cause of maternal mortality during the first trimester of pregnancy which accounts for $10-15 \%$ of all maternal deaths. ${ }^{2}$ It is a common condition in women of reproductive age group with an incidence of $1-3 \% .^{3}$ Risk factors of ectopic pregnancy include tubal surgery, previous ectopic pregnancy, infertility, chronic salpingitis, use of intrauterine contraceptive devices (IUCD), history of smoking at the time of pregnancy or any previous pelvic or abdominal surgeries. ${ }^{4}$ Patients with an ectopic pregnancy usually present with amenorrohea, abdominal pain and bleeding per vaginum between 6-10 weeks of gestation. ${ }^{5}$ Due to early diagnosis there seems to be an increasing trend in the incidence of ectopic pregnancy but the incidence of maternal morbidity and mortality has declined due to early diagnosis by serial $\beta$ HCG measurements, transvaginal ultrasonography and minimally invasive surgery(MIS). ${ }^{6}$ Early diagnosis reduces the risk of tubal rupture and allows for conservative medical management. ${ }^{7}$ This retrospective analysis of ectopic pregnancy was done to determine the incidence, age, risk factors, clinical features, modalities 
of treatment, morbidity and mortality associated with ectopic pregnancy in a teritary care hospital in this part of the country. With this information we can anticipate, make an early diagnosis and reduce the morbidity. We can also reduce the incidence of ectopic pregnancy to some extent by correcting some of the risk factors which predisposes for ectopic pregnancy. In those anticipated we can educate the patient accordingly as well.

\section{METHODS}

The objective of the study was to identify the age group, parity and risk factors most commonly associated with ectopic pregnancy. To know the clinical presentation, modalities of treatment employed, their efficacies and outcome of ectopic pregnancy.

\section{Inclusion criteria}

All women with ectopic pregnancies were included in this study.

\section{Exclusion criteria}

All intrauterine pregnancies.

\section{Outcome variables}

Relation of variables like age, parity, risk factors, symptoms and signs, diagnostic tools, modalities of treatment, morbidity and mortality with respect to ectopic pregnancy.

This retrospective study of ectopic pregnancy was conducted at Chettinad hospital and research institute; Chennai in the department of Obstetrics and Gynaecology over a period of 3 years from January 2014 to December 2016. 79 cases of ectopic pregnancies were diagnosed in this period. All the relevant information including history, examination findings, investigations done with the reports, modalities of treatment undertaken, outcome, etc were obtained from the case records and tabulated.

\section{Statistical analysis}

Information regarding age, parity, risk factors, clinical features, investigations, modalities of treatment as well as morbidity and mortality were collected, tabulated and analyzed with Microsoft Excel.

\section{RESULTS}

During the study period in our hospital 79 cases were diagnosed as ectopic pregnancies, giving an incidence of $3.49 \%$. Table 1 shows that incidence was highest among patients belonging to age group of 26-30 years (40.50\%). Table 2 shows the incidence between primiparas and multiparas, in which $72.15 \%$ were multiparas and $27.84 \%$ were primiparas.
Table 3 depicts the risk factors associated with ectopic pregnancy. In our study, about $72 \%$ of patients had one or more identifiable risk factors like previous abortions (18.98\%), use of IUCD (18.98\%), infertility (18.98\%), previous tubal surgery $(17.72 \%)$, previous $\mathrm{D}$ and $\mathrm{C}$ (15.18\%), previous LSCS (12.65\%), appendicectomy $(6.32 \%)$, previous ectopic $(5.06 \%)$, use of OCP's $(5.06 \%)$.

Table 1: Age-wise distribution of total patients.

\begin{tabular}{|lcc|}
\hline Age & No. of patients & $\%$ \\
\hline$<20$ & 4 & 5.06 \\
\hline $20-25$ & 18 & 22.78 \\
\hline $26-30$ & 32 & 40.50 \\
\hline $31-35$ & 20 & 25.31 \\
\hline$>35$ & 5 & 6.32 \\
\hline
\end{tabular}

The commonest presenting complaints were amenorrhoea $(89.3 \%)$, pain abdomen $(68.35 \%)$ and vaginal bleeding $(43.03 \%)$. Abdominal tenderness was present in $39.24 \%$ cases, cervical motion tenderness in $21.51 \%$ cases and adnexal tenderness in $16.4 \%$ cases. Abdominal distension present in $8.86 \%$ and vomiting in $6.32 \%$ cases. Urine pregnancy test was positive in $82.2 \%$ cases. Ultrasonography revealed ectopic in $75.94 \%$ cases. Serial $\beta$ HCG estimation were used to correlate in $54.43 \%$ cases. Incidence of ectopic pregnancy (63.28\%) was highest between July and December.

Table 2: Distribution according to parity.

\begin{tabular}{|lll|}
\hline Parity & No. of patients & $\%$ \\
\hline Primipara & 22 & 27.84 \\
\hline Multiparous & 57 & 72.15 \\
\hline
\end{tabular}

Table 4 shows that the most common site of ectopic pregnancy was in the ampullary region $(74.68 \%)$ of fallopian tube. The next common sites were fimbria and isthmus. Cornual, heterotopic and ovarian pregnancies were rare.

Table 3: Risk factors associated with ectopic pregnancy.

\begin{tabular}{|lll|}
\hline Risk factor & No. of patients & $\%$ \\
\hline No risk factors & 22 & 27.84 \\
\hline Previous abortion & 15 & 18.98 \\
\hline Infertility & 15 & 18.98 \\
\hline IUCD & 15 & 18.98 \\
\hline Previous tubal surgery & 14 & 17.72 \\
\hline Previous D and C & 12 & 15.18 \\
\hline Previous LSCS & 10 & 12.65 \\
\hline Appendicectomy & 5 & 6.32 \\
\hline Previous ectopic & 4 & 5.06 \\
\hline Use of OCP's & 4 & 5.06 \\
\hline
\end{tabular}

LSCS- Lower Segment Cesarean Section, IUCD- Intrauterine Contraceptive Device, OCP's-Oral Contraceptive Pills, *Some of them had more than one risk factors. 
Table 4: Distribution of cases according to site of ectopic pregnancy.

\begin{tabular}{|c|c|c|}
\hline Site & No. of patients & $\%$ \\
\hline Ampulla & 59 & 74.68 \\
\hline Fimbria & 6 & 7.59 \\
\hline Isthmus & 7 & 8.86 \\
\hline Ovary & 3 & 3.79 \\
\hline Cornu & 3 & 3.79 \\
\hline Heterotopic & 1 & 1.26 \\
\hline
\end{tabular}

Table 5 depicts that right sided ectopic pregnancy was present in more number of cases [55(69.62\%)], while left sided ectopic pregnancy was noted only in $24(30.37 \%)$ cases.

Table 5: Distribution according to side involved.

\begin{tabular}{|lll|}
\hline Side & No. of patients & $\%$ \\
\hline Right & 55 & 69.62 \\
\hline Left & 24 & 30.37 \\
\hline
\end{tabular}

Table 6 tells us how many came with ruptured ectopic, unruptured ectopic or tubal abortion. Ruptured ectopic was observed in $56.96 \%$ cases, unruptured ectopic in $39.24 \%$ and tubal abortion in $3.79 \%$ cases. $60.7 \%$ cases had haemoperitoneum.

Table 6: Distribution according to condition of tube.

\begin{tabular}{|lll|}
\hline $\begin{array}{l}\text { Condition of ectopic } \\
\text { pregnancy }\end{array}$ & No. of patients & $\%$ \\
\hline Ruptured & 45 & 56.96 \\
\hline Unruptured & 31 & 39.24 \\
\hline Tubal abortion & 3 & 3.79 \\
\hline
\end{tabular}

Table 7: Modalities of management employed.

\begin{tabular}{|lll|}
\hline Line of management & No. of patients & $\%$ \\
\hline Expectant management & 02 & 2.53 \\
\hline Medical & 27 & 34.17 \\
\hline $\begin{array}{l}\text { Unilateral complete } \\
\text { Salpingectomy }\end{array}$ & 29 & 36.70 \\
\hline Bilateral Salpingectomy & 07 & 8.86 \\
\hline Salphingo-opheroectomy & 04 & 5.06 \\
\hline Fimbriectomy & 03 & 3.79 \\
\hline Cornual Resection & 03 & 3.79 \\
\hline Partial Salpingectomy & 02 & 2.53 \\
\hline Laproscopic Partial & 02 & 2.53 \\
\hline Salpingectomy & & \\
\hline
\end{tabular}

Table 7 shows about the mode of management adopted in different cases. 2 (2.53\%)cases were managed expectantly, 27(34.17\%) cases underwent medical line of management. 50 cases $(63.29 \%)$ underwent surgery. The most common surgery done was unilateral complete salpingectomy in 29 cases $(36.70 \%)$, bilateral salpingectomy in $7(8.86 \%)$, salpingo-oopherectomy in 4 $(5.06 \%)$, fimbrectomy in $3(3.79 \%)$, cornual resection in
$3(3.79 \%)$, partial salpingectomy in $2(2.53 \%)$ and laparoscopic partial salpingectomy in $2(2.53 \%)$.

Maternal morbidity included need for blood transfusion, ICU admissions (as some were in hypovolemic shock on admission) and wound gaping. 28 (35.44\%) cases needed blood transfusion, $3(3.79 \%)$ cases required ICU admission. $2(2.53 \%)$ cases had sepsis, 1 (1.26\%) had wound gaping. No maternal mortality observed.

\section{DISCUSSION}

The incidence of ectopic pregnancy in our study was $3.49 \%$ which was high when compared to studies conducted by Wakankar et al (1.99\%), Khaleeque et al $(1.3 \%)$, etc. ${ }^{8,9}$

Majority of our patients $(40.50 \%)$ belonged to age group of 26-30 years. Indian women mostly marry at an early age and complete their families early and hence probably the high incidence in this age group. Next most common age group associated with ectopic pregnancy was between 31-35 years. Hoover KW and colleagues reported that, rate of ectopic pregnancy increases with increasing age, $0.3 \%$ among girls and women aged 15-19 years and $1.0 \%$ among women aged $35-44$ years. ${ }^{10}$

Multiparous women have higher incidence than primiparas. This may be due to previous abortions and infections which causes tubal damage. In present study $72.15 \%$ were multiparas and $27.84 \%$ were primiparas. This was consistent with results of Wakankar et al and Khan et al. ${ }^{8,11}$

$72 \%$ of our patients had one or more risk factors of which abortion was the commonest risk factor $(18.98 \%)$ which is in comparison with Prasanna et al study (16\%), Shetty and Shetty study (29\%). ${ }^{12,13}$ Post abortal infection leads to tubal damage and thus increases the chances of ectopic pregnancies.15 women with IUCD had ectopic pregnancy. IUCD prevents intrauterine pregnancy but not tubal or ovarian pregnancy. Other risk factors included infertility $(18.98 \% \%)$, tubal surgery $(17.72 \%)$, previous $\mathrm{D}$ and C (15.18\%), previous LSCS ((12.65\%), appendicectomy $(6.32 \%)$, previous ectopic $(5.06 \%)$ and use of OCP's (5.06\%). Similar risk factors were noted in various other studies like that of Gupta et al, Rashmi Gaddagi et al. ${ }^{14,15}$ There is increased chance of repeat ectopic with previous ectopic because tubal pathology is almost bilateral. Identifying the various risk factors help in early diagnosis and conservative management including medical or minimally invasive surgery (MIS).

The most common presenting symptoms were amenorrhoea (89.3\%), pain abdomen (68.35\%) and vaginal bleeding (43.03\%). Abdominal tenderness was present in $39.24 \%$ cases, cervical tenderness in $21.51 \%$ cases and adnexal tenderness in $16.4 \%$ cases. Abdominal distension was seen in $8.86 \%$ and vomiting in $6.32 \%$ cases. All these were helpful in diagnosing ectopic 
pregnancy. Classical triad of symptoms (abdominal pain, amenorrhoea and vaginal bleeding) was noted in 32 patients. This triad of amenorrhoea, pain abdomen and vaginal bleeding has been typically described to be associated with ectopic pregnancy in number of standard textbooks. There was one lady, primi gravida with irregular periods, at 5-6weeks of gestation. $\beta$ HCG was suggestive of pregnancy but it was not localised on ultrasound. When asked to return with repeat Serum $\beta$ HCG after 48 hours, she came with complaints of left shoulder pain, vomiting and slight abdominal pain, Cullen's sign was positive. She had to undergo unilateral salpingectomy for chronic ruptured ectopic pregnancy. The ruptured ectopic pregnancy was missed on ultrasound in the first instance. There were no unusual symptoms observed in our study which could be associated with ectopic pregnancy.

Urine pregnancy test was done in 66 cases which was positive in $65(82.27 \%)$ cases. Though UPT is known for its poor sensitivity, in our study only one case of ectopic pregnancy was negative for UPT. In the remaining 13 $(16.45 \%)$ cases UPT was not done as they were taken up directly for laparotomy in view of strong clinical suspicion of ruptured ectopic pregnancy. Ultrasonography revealed ectopic in $75.94 \%$ cases which is comparable to study conducted by Shetty and Shetty. ${ }^{13}$ Ultrasound revealed heteroechoic mass in 25 cases, free fluid in 28 cases, gestational sac with cardiac activity was noted in only 2 cases. Though transvaginal ultrasound is a helpful diagnostic tool in ectopic pregnancy (ruptured or unruptured), it is also notorious for missing the diagnosis. But in our study only one case of ectopic pregnancy for which ultrasound was done, was missed. Culdocentesis was done in one patient to confirm rupture and $5 \mathrm{ml}$ of frank blood was drawn and taken up for laparotomy. $\beta$ HCG was done in 43 cases to support the diagnosis.

Seasonal variation was noted in the current study. Majority of cases (63.29\%) were found between July and December which was in comparison with study by Shetty and Shetty $(61.3 \%) .{ }^{13}$ Due to the influence of season on ovarian activity, the highest incidence was found to be in winter season. ${ }^{16}$

The most common site of ectopic pregnancy was observed to be in the ampullary region of fallopian tube, noted in $74.68 \%$ cases. This was in comparison with Chow et al study $(79.6 \%) .{ }^{17}$ Other sites were fimbrial $(7.59 \%)$, isthmic $(8.5 \%)$, cornual $(3.79 \%)$, ovarian $(3.79 \%)$, heterotopic $(1.26 \%)$. Heterotopic pregnancy is rare occurring in $<1 / 30,000$ pregnancies in natural conception cycles. ${ }^{18}$ In our study there was only one case of heterotopic pregnancy with intrauterine twin gestation and left tubal ectopic gestation, conceived by ART. Expectant line of management was employed in this case. Presently she is continuing with her intrauterine twin pregnancy. Right sided ectopic pregnancy (69.92\%) was more common than left side $(30.37 \%)$ in comparison with studies by Khaleeque et al, Shetty and Shetty. ${ }^{9,13}$
Ruptured ectopic was observed in $56.96 \%$ cases, unruptured ectopic in $39.24 \%$ and tubal abortion in $3.79 \%$ cases in the present study. In Latchaw et al study tubal rupture was found in $59 \%$ cases and $41 \%$ had unruptured ectopic pregnancies. ${ }^{19} 60.7 \%$ cases of our study showed haemoperitoneum on laparotomy.

Out of $31(39.24 \%)$ unruptured cases, 27 (34.17\%) cases were medically managed, $2(2.53 \%)$ cases were managed expectantly and $2(2.53 \%)$ were taken up for surgery. In those who were medically managed, single dose regimen was followed in 15 cases, multi dose regimen with folinic acid reserve in 6 cases, two dose regimens without folinic acid reserve was given in 6 cases. According to the study conducted by Mahboob et al, $28.8 \%$ cases had undergone medical management and $13.3 \%$ underwent expectant management. ${ }^{2}$ Similar results were found in Moradan study. ${ }^{20}$ In present study, all medically managed cases were successful except for one case which had to be taken up for laparotomy. One should also emphasize on careful selection of cases and appropriate regimens while opting for medical management.

$63.29 \%$ cases underwent laparotomy in which the common procedures done were unilateral complete salpingectomy (36.70\%), bilateral salpingectomy $(8.86 \%)$, salpingo-oopherectomy $(5.06 \%)$, fimbrectomy $(3.79 \%)$, cornual resection $(3.79 \%)$, partial salpingectomy $(2.53 \%)$ and laproscopic partial salpingectomy $(2.53 \%)$. The results were more or less close to study done by Rashmi Gaddagi et al. ${ }^{15}$ In our study one patient who had attempted medical abortion not knowing she had an ectopic pregnancy, came with ruptured ectopic. She underwent laproscopic salpingectomy. This emphasises the requirement to confirm intrauterine pregnancy before attempting medical abortion. Public awareness has to be created not to take over-the-counter MTP pills to attempt medical abortion.

Morbidity includes anaemia, ICU admissions and wound gaping. $8(35.44 \%)$ cases needed blood transfusion, 3 $(3.79 \%)$ cases required ICU admission as they came in shock of which $2(2.53 \%)$ cases had sepsis. 1 (1.26\%) case had wound gaping for which resuturing was done. No mortality was noted in our study showing similarity with Abbas A and Akram H study. ${ }^{21}$

\section{CONCLUSION}

As is evident by results of our study and various other studies in India and abroad, there is a rising trend in the incidence of ectopic pregnancy. This can be attributed to various factors some of which are preventable. The risk of abortions, D and C's, PID can be reduced by increasing the awareness among women, the options for safe sexual practices and contraceptives. Early diagnosis remains the mainstay in reducing the morbidity in those cases, were we cannot prevent ectopic pregnancies. High index of clinical suspicion, serial serum $\beta$ HCG estimation, transvaginal ultrasound findings all help in 
this aspect. Though this is the age of microinvasive surgery (MIS) and conservative management, we had to opt for laparotomy in 50 cases. The reason being 45 cases came with ruptured ectopic pregnancies. Careful selection of cases for medical management also determines their success rate. Fortunately, in our study there was not much maternal morbidity and no mortality due to early diagnosis and prompt treatment. Still ectopic pregnancy remains a diagnostic dilemma and is missed many a times.

Funding: No funding sources Conflict of interest: None declared

Ethical approval: Not required

\section{REFERENCES}

1. Howard W, John A. Rock, Ectopic pregnancy. Telinde's Operative Gynaecology. $11^{\text {th }}$ ed. Philadelphia, Lippincott Williams and Wilkins; 2015:798.

2. Mahboob U, Mazhar SB. Management of ectopic pregnancy: a two-year study. J Ayub Med Coll Abbottabad. 2006;18(4):34-7.

3. Farquhar CM. Ectopic pregnancy. Lancet. 2005;366:583-91.

4. Chaturvedi S. Trends of ecotopic pregnancy in the state-an institutional based retrospective study. J Adv Med Dental Sci Res. 2016;4(6).

5. Walker JJ. Ectopic Pregnancy. Clin Obstet Gynecol. 2007;50:89-99.

6. Timmerman D. Predictive models for the early diagnosis of ectopic pregnancy. VerhandelingenKoninklijke Academie voor Geneeskunde van Belgie. 2003;66(2):155-71.

7. Barnhart KT. Ectopic pregnancy. N Engl J Medicine. 2009;361(4):379-87.

8. Wakankar R, Kedar K. Ectopic Pregnancy-A rising Trend. Int J Sci Stud. 2015;3(5):18-22.

9. Khaleeque F, Siddiqui RI, Jafarey SN. Ectopic pregnancies: a three-year study. JPMA. 2001;51(7):240-3.

10. Yeasmin MS, Uddin MJ, Hasan E. A Clinical Study of Ectopic Pregnancies in a Tertiary Care Hospital of Chittagong, Bangladesh. Chattagram Maa-O-Shishu Hospital Med College J. 2014;13(3):1-4.

11. Hoover KW, Tao G, Kent CK. Trends in the diagnosis and treatment of ectopic pregnancy in the
United States. Obstetrs Gynecol. 2010;115(3):495502.

12. Khan B, Deeba F, Khan WA. year review of 255 cases of ectopic pregnancy. J Androl Gynecol. 2013;1(2):4.

13. Prasanna B, Jhansi CB, Swathi K, Shaik MV. A study on risk factors and clinical presentation of ectopic pregnancy in women attending a tertiary care centre. IAIM. 2016;3(1):90-6.

14. Shetty S, Shetty A. A clinical Study of Ectopic Pregnancies in a Tertiary care hospital of Mangalore, India. Innovative J Medic Heal Sci. 2014;4(1).

15. Gupta R, Porwal S, Swarnkar M, Sharma N, Maheshwari P. Incidence, trends and risk factors for Ectopic Pregnancies in a tertiary care hospital of Rajasthan. Journal of Pharmaceutical and Biomedical Sciences (JPBMS). 2012;16(16):16.

16. Gaddagi RA, Chandrashekhar AP. A clinical study of ectopic pregnancy. J Clin Diagn Res. 2012;6(5):867.

17. Warren CW, Gwinn ML, Rubin GL. Seasonal variation in conception and various pregnancy outcomes. Social biology. 1986;33(1-2):116-26.

18. Chow WH, Daling JR, Cates W, Greenberg RS. Epidemiology of ectopic pregnancy. Epidemiologic reviews. 1987;9(1):70-94.

19. Ludwig M, Kaisi M, Bauer O,Diedrick K.Heterotropic pregnancy in a spontaneous in a spontaneous cycle : do not forget about it! Eur J Obstet Gynecol Reprod Biol. 1999;87(1):91-93.

20. Latchaw G, Takacs P, Gaitan L, Geren S, Burzawa J. Risk factors associated with the rupture of tubal ectopic pregnancy. Gynecol Obstet Invest. 2005;60(3):177-80.

21. Sanam Moradan MD, Family M. A Hospital based analysis of 71 cases of ectopic pregnancies, Risk factors and management. Retrospective Observational Study. SEAJCRR. 2014;3(6):1054-59.

22. Abbas A, Akram H. Ectopic pregnancy; audit at maula bakhsh teaching hospital Sargodha. Professional Med J. 2011;18(1):24-27.

Cite this article as: Sindhura M, Sailatha R, Famida AM, Vijayalakshmi K, Sathiya S, Renuka S. Trends in ectopic pregnancy: a retrospective clinical study of 79 cases. Int J Reprod Contracept Obstet Gynecol 2017;6:3009-13. 